DENIS MORELLI

OS ÓRGÃOS TÉCNICOS E CONSULTIVOS DA SOCIEDADE ANÔNIMA

FACULDADE DE DIREITO DA UNIVERSIDADE DE SÃO PAULO

SÃO PAULO - 2012 
DENIS MORELLI

\title{
OS ÓRGÃOS TÉCNICOS E CONSULTIVOS DA SOCIEDADE ANÔNIMA
}

\author{
Departamento de Direito Comercial
}

Orientador: Professor Francisco Satiro de Souza Junior

Dissertação apresentada à Faculdade de Direito da Universidade de São Paulo para a obtenção do título de Mestre em Direito Comercial.

FACULDADE DE DIREITO DA UNIVERSIDADE DE SÃO PAULO

SÃO PAULO - 2012 


\section{RESUMO}

Esta dissertação tem o objetivo de estudar os órgãos técnicos e consultivos da sociedade anônima, em sua configuração mais contemporânea, segundo a qual são mais conhecidos como os comitês da sociedade anônima.

Para isso, serão avaliados os movimentos internacionais que têm exercido influência na criação desses órgãos nas companhias brasileiras. Esses movimentos estão intrinsecamente ligados às forças de convergência dos padrões internacionais de governança corporativa, tema que também é apreciado no decurso do trabalho.

Após, a dissertação cuidará de avaliar as medidas externadas em âmbito nacional, que demonstram a tendência à adaptação dos referidos padrões internacionais de governança corporativa, com recomendações, e também algumas determinações, para que as companhias criem os comitês nas suas estruturas.

Ao final, serão avaliadas algumas consequências jurídicas da implantação dos comitês no Brasil, conforme a concepção moderna que se tem para esses órgãos. 


\begin{abstract}
This master's degree dissertation aims to discuss the technical and advisory bodies of corporations, contemporarily known as corporate committees.

In order to achieve its goals, the study will take into consideration the international trends that have influenced the creation of these bodies in Brazilian companies. These trends are closely linked to an international effort towards the convergence of corporate governance standards, which will also be analyzed in this dissertation.

Furthermore, this dissertation will explore the measures taken to substantiate and adapt these international standards of corporate governance to a domestic setting. Such measures include both recommendations and mandatory provisions to create corporate committees.
\end{abstract}

Finally, this dissertation will analyze certain legal consequences of the deployment committees in Brazil, taking into consideration the modern understanding of these bodies. 


\section{PALAVRAS-CHAVE}

Órgãos técnicos e consultivos. Comitês. Comitês de Auditoria. Governança Corporativa. Conselhos de Administração. 


\section{CAPÍTULO I - INTRODUÇÃo}

Os órgãos da Sociedade Anônima, criados pelo estatuto, com funções técnicas ou destinados a aconselhar os administradores não têm recebido atenção da doutrina nacional ao longo do último decênio. Seguramente, um dos fatores para que isso tenha ocorrido consiste no fato de que, até então, tais órgãos não praticavam atos de relevo nas companhias brasileiras, que dessem razão para algum debate mais consistente.

Esse quadro, no entanto, mudou sensivelmente nos últimos anos, sendo verificada presença cada vez mais marcante desses órgãos nas companhias, tanto no Brasil como no mundo. Na configuração mais moderna, esses órgãos são mais conhecidos como os "Comitês"1 das Sociedades Anônimas.

Essa mudança, na verdade, está inserida em um contexto que extrapola a realidade brasileira, pois se relaciona com as grandes mudanças que afetaram o ambiente societário e de mercado de capitais global.

Notadamente, a ocorrência de diversos escândalos corporativos nos Estados Unidos da América, a partir do ano 2000, envolvendo, entre outras, as companhias Enron e WorldCom., tornou pública uma série de fraudes contábeis extremamente graves. Logo nas primeiras avaliações sobre essas ocorrências, foi possível apurar que tais fraudes só

\footnotetext{
${ }^{1}$ Reconhece-se, desde logo, que o termo "Comitê" pode ser utilizado para designar uma série de outras coisas, que não órgãos das companhias. Inclusive na seara pública e governamental, o termo é vastamente utilizado, como é o caso do Comitê de Política Monetária (Copom), do Comitê de Pronunciamentos Contábeis (CPC) e do Comitê de Supervisão Bancária de Basileia (em inglês, Basel Committee on Banking Supervision - BCBS), por exemplo.

A expressão costuma designar a "reunião de pessoas que visam a um interesse determinado" e tem origem no anglo-francês commettee (1495), do latim committère "confiar, entregar, comunicar". Por essa razão, a palavra não é sequer reconhecida por puristas da gramática da língua portuguesa, pois é considerada galicismo e deveria ser substituída por "junta ou comissão" (Houaiss da Língua Portuguesa. Versão online).

Não obstante, hodiernamente, e conforme se demonstrará no decorrer deste trabalho, utilização deste termo é presente na quase totalidade das regras normativas recentes, para designar os órgãos técnicos e consultivos das sociedades anônimas. Da mesma forma, a palavra se faz presente nas alterações mais recentes dos estatutos sociais das companhias nacionais.

Assim, neste trabalho, o termo "Comitê" será utilizado para se referir aos órgãos técnicos e consultivos da sociedade anônima (a não ser que se especifique o contrário). Ou seja, Comitê é a designação que abreviará o próprio objeto de estudo do trabalho, doravante.
} 
puderam ser concretizadas em razão de sérias falhas nos sistemas de controle de auditoria daquelas empresas ${ }^{2-3}$.

Esses escândalos corporativos deram azo a uma verdadeira crise de confiança no mercado de capitais.

Nos Estados Unidos, a reação ${ }^{4}$ a essas ocorrências levou ao reestudo da importância dos Comitês de Auditoria e o seu papel na governança corporativa das companhias. Como resultado, foi editado o Sarbanes-Oxley Act de 2002, que dispôs, entre outras coisas, sobre esses Comitês e a sua atuação.

As medidas positivadas com o Sarbanes-Oxley Act tiveram o objetivo comum de aperfeiçoar o processo de disclosure das informações financeiras e, com isso, trazer maior credibilidade para os mercados em que as companhias operam. Foram impostas mudanças profundas nas organizações das companhias participantes do maior mercado de capitais mundial.

A notoriedade e a relevância desses acontecimentos provocaram, de maneira igualmente relevante, alterações nas práticas de governança corporativa de diversos países, os quais rapidamente acataram, de alguma forma, o modelo proposto naquela lei estadunidense.

No Brasil, ainda que os Comitês de Auditoria não tenham se tornado obrigatórios para todas as companhias abertas brasileiras, não há como negar que o Sarbanes-Oxley Act gerou efeitos internamente ${ }^{5}$. As companhias brasileiras emissoras de

\footnotetext{
${ }^{2}$ Em artigo sobre a crise corporativa citada, Robert HAMILTON cita que os problemas atingiram uma série de companhias do setor de telecomunicação, com destaque, além da WorldCom., à Adelphia Communications Co.; Qwest Communications International Ic.; e Global Crossing, Ltd.; XO Communications, Inc. Já em setores diversos ao da telecomunicação (non-telecom), evidenciam-se o caso da própria Enron, bem como da Tyco International, Ltd.; ImClone Systems, Inc.; General Eletric Co.; e Xerox Corp.

HAMILTON, Robert W. The Crisis in Corporate Governance: 2002 Style in 40 Houston Law Review, 2003, pgs. 19 a 32.

${ }^{3}$ VERSCHOOR, Curtis C. Audit Committee Essentials. New Jersey: Wiley, 2008, pgs. 6 e 7.

${ }^{4}$ Assim se explica o contexto desta reação:

"Given the notoriety of the Enron collapse and its talismanic role in justifying an intrusive reform programme that has transformed the corporate governance regime in the United States, the approach was a rational, if problematic, use of the adversarial legal method."

Os eventos, que precederam a edição do Sarbanes-Oxley Act, compõem o que alguns autores chamam de "era of corporate fraud".

O'BRIEN, Justin. Redesigning Financial Regulation. New Jersey: Wiley, 2007, p. 7.

${ }^{5}$ Conforme se verá adiante, a Resolução CMN no 3.198, de 27 de maio de 2004, obrigou todas "instituições financeiras e demais instituições autorizadas a funcionar pelo Banco Central do Brasil, exceto as sociedades de crédito ao microempreendedor", a criar um comitê de auditoria, como órgão estatutário.
} 
American Depositary Receipt - ADRs ${ }^{6}$, por exemplo, por possuírem listagem nas Bolsas norte-americanas, tiveram que se adequar às novas regras do Sarbanes-Oxley Act, com a comprovação de que possuíam, em suas estruturas, um Comitê de Auditoria, ou órgão equivalente ${ }^{7}$.

Assim, o estudo dos Comitês de Auditoria, frente à recente demanda pelas suas atividades em todo o mundo, mostrar-se-á indispensável para o desenvolvimento da dissertação a ser elaborada, até pela quantidade de artigos acadêmicos, produzidos principalmente no exterior, específicos sobre o assunto. Esses estudos, antes de tudo, servem como indicativos da importância dos Comitês para as companhias abertas e das suas funções dentro da organização societária.

Todavia, não serão só os Comitês de Auditoria que importarão para o trabalho que será desenvolvido. Isso porque os recentes acontecimentos ao redor do mundo, que enfatizam a importância do aperfeiçoamento de práticas de governança corporativa, têm enaltecido a relevância de variadas espécies de Comitês. Nesse contexto, o Sarbanes-Oxley Act é um entre vários fatores históricos que têm, ao longo dos anos, demandado o aprimoramento das estruturas internas das companhias, em atenção aos princípios de governança corporativa internacionalmente aceitos.

Tais princípios de governança, muitas vezes concebidos no exterior, têm sido, cada vez mais, disseminados e aplicados nas companhias brasileiras - o que, em larga medida, possui correlação com o notório fortalecimento e crescimento do mercado de capitais brasileiro ao longo dos últimos anos.

Com efeito, acompanhado de uma série de alterações na macroeconomia brasileira, que possibilitaram a estabilidade da moeda e das taxas de câmbio e juros, o mercado de capitais nacional, a partir de meados de 2002, sofreu o impacto de importantes mudanças na sua estrutura regulatória ${ }^{8}$.

\footnotetext{
${ }^{6}$ Os ADRs são recibos de ações (Depositary Receipt) que permitem que empresas sediadas em outros países - no caso, companhias brasileiras - possam negociar seus papéis no mercado norte-americano.

${ }^{7}$ Ver notas 47 e 148 e textos relacionados.

${ }^{8}$ Otavio Yazbek, em seu trabalho sobre a regulação do mercado financeiro e de capitais, assevera o seguinte, sobre as alterações sofridas no Brasil:

“Apenas com a estabilização monetária, em meados da década de 1990, e com a correspondente integração do país na ordem financeira mundial, como "país emergente", em grande parte dependente de recursos externos, tornou-se possível (mais do que isso, tornou-se necessária) a revalorização das estruturas regulatórias. Assim, a supra-referida 'tecnicização' das práticas de regulação financeira no Brasil, agora
} 
E, quase que como um círculo virtuoso, o aumento nos números de ofertas públicas iniciais de ações, acompanhado do massivo ingresso de capital estrangeiro na economia, acabou por trazer consigo a necessidade do aprimoramento do aprimoramento das práticas de governança corporativa até então predominantes no cenário nacional.

Uma das conhecidas medidas adotadas no Brasil, com vistas a incrementar as boas práticas de governança, foi a criação do "Novo Mercado", pelo qual foram estabelecidos diferentes segmentos de listagem para as companhias abertas que possuíam ações negociadas na então Bolsa de Valores de São Paulo - Bovespa 9 .

Com a participação nesse segmento especial de listagem de ações, as companhias se comprometem, voluntariamente, a adotar as boas práticas de governança corporativa, em uma ação adaptativa à nova realidade do mercado de ações brasileiro. Entre as regras vigentes para o ingresso no Novo Mercado, estão medidas de maior proteção aos acionistas minoritários, com o objetivo de balancear o amplo poder que, em grande parte dos casos, é concentrado nas mãos dos acionistas controladores das companhias brasileiras.

Apesar do advento do Novo Mercado, e dos elogios à sua implantação, o problema do conflito de interesses entre acionistas controladores e minoritários, típico do mercado brasileiro, prosseguiu como constante objeto de debate. É com essa preocupação que os Comitês passaram a ser sugeridos no Brasil, para que esses órgãos sirvam para

coerentes com o que se entende como a 'racionalidade econômica' aplicável à matéria, apenas ocorreu no último decêncio"

YAZBEK, Otavio. Regulação do Mercado Financeiro e de Capitais. Rio de Janeiro: Elsevier, 2007, p. 278.

${ }^{9} \mathrm{Na}$ analise das alterações na ordem econômica, que provocaram mudanças no cenário corporativo nacional, bem como da implantação do Novo Mercado, MuNHOZ expõe o seguinte:

"A observação dessa realidade permite concluir que se, por um lado, as regras de governança corporativa adotadas pelo Novo Mercado não podem ser consideradas fator suficiente para o desenvolvimento do mercado de capitais (exerceram papel determinante fatores de ordem econômica como aqueles antes destacados), por outro, é indubitável que foi fundamental para tal desenvolvimento a presença de um quadro normativo de maior proteção às minorias e que oferece maior confiança e credibilidade para os investimentos.

(...)

Foi nesse contexto que, nos últimos anos, a doutrina societária brasileira passou a dedicar grande atenção aos estudos sobre governança corporativa, sendo marcante a influência nesses estudos do modelo norteamericano."

MUNHOZ, Eduardo Secchi. Desafios do Direito Societário Brasileiro na Disciplina da Companhia Aberta: Avaliação dos sistemas de controle diluído e concentrado in Direito Societário, Desafios Atuais. São Paulo: Quartier Latin, 2009, p. 122. 
solucionar - ou ao menos atenuar - eventuais conflitos existentes no âmago da Companhia $^{10}$.

Os Comitês, assim, gradualmente passaram a ser recomendados tanto pelo órgão de regulação do mercado de capitais nacional, a Comissão de Valores Mobiliários CVM, quanto por entidades de autorregulação.

Exemplo disso é o Parecer de Orientação CVM n 35 , de $1^{\circ}$ de setembro de 2008, o qual, com fundamento na "experiência internacional acerca da interpretação dos deveres fiduciários dos administradores", sugere a criação de um Comitê Especial Independente para as companhias que realizam operações de fusão, incorporação e incorporação de ações envolvendo a sociedade controladora e suas controladas ou sociedades sob controle comum. As atribuições desse Comitê seriam negociar os termos das operações e submeter suas recomendações ao Conselho de Administração. O objetivo final do Comitê referido é, portanto, assegurar a independência na negociação da operação e mitigar o risco de que a relação de troca de ações na operação não seja comutativa.

Conforme se procurará demonstrar no decorrer deste trabalho, a criação gradativa pelas companhias de uma série de Comitês é algo que tem sido progressivamente incentivado pelos órgãos reguladores e entidades de autorregulação. Como já se pode adiantar, a presença crescente dos Comitês nas companhias nacionais tem relação direta com a incorporação das práticas de governança corporativa adotadas internacionalmente. E sendo a governança corporativa um fator de suma importância para o estudo das sociedades anônimas, o estudo dos Comitês ganha relevo, já que, afinal, é um dos trata-se de um dos mecanismos mais recomendados nas propostas de soluções para os problemas enfrentados pelas companhias hodiernamente.

Nesse aspecto, é relevante considerar que a análise das práticas de governança modernas afetam o estudo do padrão de conduta (standard) esperado para os trabalhos dos Comitês e os atos praticados pelos seus membros. Somente por esse motivo,

${ }^{10} \mathrm{O}$ professor Calixto, em outra obra de sua autoria, aponta que a criação de órgãos independentes é uma alternativa moderna para uma solução, orgânica ou estrutural, dos conflitos existentes na companhia, inclusive aquele entre o entre minoritário e o controlador:

"Por solução orgânica ou estrutural quer-se significar a tentativa de resolver nos órgãos societários o problema do conflito, seja através da incorporação no órgão de todos os agentes que têm interesse ou sofrem as consequências, ou através da criação de órgãos independentes, não passíveis de ser influenciados pelos interesses conflitantes."

SALOMÃO FILHO, Calixto. O novo direito societário, 4ª ed., São Paulo: Malheiros, 2011, pgs. 104 e 105. 
já sobressai a importância do estudo jurídico dos Comitês nas companhias abertas brasileiras, pois os deveres dos Comitês e seus membros, conforme a legislação vigente, deverão ser interpretados de acordo com essa nova realidade.

De outro turno, deve-se ter em mente que a mera transposição formal das práticas internacionais, pelas companhias brasileiras, certamente não é suficiente para que os Comitês cumpram devidamente a sua função, dentro desse novo cenário. O que se espera são resultados concretos dos atos de governança adotados - e, particularmente, dos Comitês, que passam a ter papel importante dentro da estrutura orgânica das companhias.

Sobre o assunto, em recente decisão proferida no Processo Administrativo Sancionador CVM $n^{\circ} 18 / 08^{11}$, na qual se avaliou a atuação de membros dos Comitês nas companhias nacionais, o diretor Otavio Yazbek ponderou acerca da adaptação efetiva das companhias brasileiras à recente dimensão complexa em que foram inseridas (no caso, particularmente, a complexidade referia-se às operações com instrumentos financeiros, que, mal monitoradas, acarretaram risco de continuidade à atividade da companhia):

"O presente caso evidencia, a meu ver, que o advento de novas estratégias financeiras e o surgimento de novas operações não foram acompanhados de mudanças nas estruturas de governança das empresas, nos mecanismos pelos quais as empresas são geridas e a sua gestão é controlada.

$\mathrm{Na}$ verdade, muitas vezes os aprimoramentos, o discurso sobre 'governança' ou os mecanismos de controles internos nem mesmo são criados para responder a essa nova realidade financeira, a esse novo mundo em que as empresas atuam, mas muito mais em resposta a tendências, quase como um reflexo condicionado. E entre não adotar as soluções adequadas ou adotá-las apenas por mimetismo, sem atenção às reais necessidades da empresa e meramente a partir de uma receita pronta, a distância parece-me pequena. (...)

\footnotetext{
${ }^{11}$ Julgado em 14/12/2010.

Disponível em:www.cvm.gov.br.
} 
Começa, aí, uma progressiva e natural evolução daquele standard de zelo e diligência: se os conselheiros não podem fiscalizar diretamente, se muitas vezes lhes falta habilidade técnica, que se criem mecanismos que lhes permitam, de maneira mediada, apreender essa realidade e deliberar, ao cabo, de maneira informada. É aí que entram Comitês consultivos e uma série de outros mecanismos, regras e procedimentos, usualmente caracterizados sob a rubrica 'controles internos'."12

Destaca-se, assim, a atribuição aos Comitês de funções típicas de controle das atividades e dos atos da administração da companhia. Essa acepção dos Comitês trazida de experiências internacionais - de órgãos de controle nas companhias traz, evidentemente, sérias implicações, sobre as quais se discorrerá ao longo do presente estudo.

Sobre o tema, é oportuno relembrar lição o professor COMPARATO, na sua famosa obra sobre o Poder de Controle na Sociedade Anônima, segundo a qual: "não é, portanto, absurdo falar-se atualmente, em português, de 'controle do controle', problema aliás fundamental de toda organização social"13. Na frase citada, a primeira acepção de controle consistiria "não só vigilância, verificação, fiscalização, como ato ou poder de dominar, regular, guiar ou restringir"; a segunda acepção representaria um "sentido forte de poder de dominação"14. O "controle do controle" poderia ser traduzido, entre as muitas variáveis, como o ato de guiar ou fiscalizar o poder contido nas companhias; poder esse detido, conforme o caso, por eventuais controladores e, principalmente, pelos administradores das companhias.

Nesse contexto, a ambiguidade semântica do termo "controle", na forma apresentada pelo professor COMPARATO, serve para ilustrar o cerne do trabalho que se

\footnotetext{
${ }^{12}$ Voto do Diretor Otavio Yazbek no Processo Administrativo Sancionador $n^{\circ}$ 18/2008, disponível em www.cvm.gov.br.

${ }^{13}$ COMPARATO, Fabio Konder. O poder de controle na sociedade anônima. $3^{\mathrm{a}}$ ed. Rio de Janeiro: Forense, 1983, p. 14

${ }^{14}$ Sendo essa a definição de controle utilizada para todo o trabalho do renomado professor. COMPARATO, Fabio Konder. O poder de controle na sociedade anônima, cit., ps. 14 a 16.
} 
pretende desenvolver, qual seja: a função dos Comitês nas sociedades anônimas ${ }^{15}$, de acordo com a realidade atual das companhias brasileiras e a legislação vigente.

Em outras palavras, serão avaliadas, com base em estudos mais recentes, as hipóteses em que os Comitês, como órgãos técnicos e consultivos das sociedades anônimas, exercem algum tipo de controle do poder nas sociedades anônimas ou, em sentido oposto, em quais hipóteses tais órgãos, ainda que existentes, exercem funções consideradas de menor relevo, sem grande interferência para os negócios das companhias.

O estudo das regras de governança prevalecentes no Brasil e no mundo ${ }^{16}$, combinado com a análise histórica da evolução da presença dos Comitês nas companhias, visará à obtenção de subsídios sobre as implicações jurídicas das atividades por eles realizadas.

Com um panorama da real situação dos Comitês no ambiente societário, procurar-se-á estabelecer alguns pontos que definem o novo standard de conduta vigente para esses órgãos nas companhias.

Em última análise, serão sistematizadas, com foco na atual conjuntura, algumas consequências fático-jurídicas dos trabalhos que tais Comitês produzem, em

\footnotetext{
${ }^{15}$ O professor Waldírio Bulgarelli, ao descrever a motivação para o seu estudo do Conselho Fiscal, pondera que todos os órgãos que compõem a estrutura organizacional das companhias - especialmente aqueles criados para o "controle do poder" - merecem ser avaliados criteriosamente:

"sendo inafastável a existência de instrumentos de controle sobre o poder, parece também indescartável um órgão do tipo do Conselho Fiscal (...). Razão pela qual não há de se considerar um trabalho sobre esse órgão como obra de circunstância (salvo, é claro, pelas motivações de oportunidade), já que se impõe a constante avaliação crítica dos institutos que integram o modelo jurídico das companhias”. BULGARELLI, Waldírio. O Conselho Fiscal nas Companhias Abertas Brasileiras. São Paulo: Revista dos Tribunais, 1988, p. 13.

${ }^{16}$ Sobre a sociologia e dogmática no direito comparado, Ascarelli aponta o seguinte:

"O estudo do direito comparado permite a construção de vários institutos, no terreno desse direito, isto é, consideradas as características de cada instituto e não relativamente a determinado sistema, mas em muitos sistemas e, por isso, segundo características internacionalmente constantes, distinguindo as características comuns das particulares.

O estudo do direito comparado pertence aos estudos históricos e sociológicos do direito; visa, antes de mais nada, ao conhecimento do direito efetivamente aplicado, da law in action; não o descobrimento da regra jurídica que, consoante um determinado sistema, seria de aplicar ao caso.

Exata, por isso, a contraposição do direito comparado aos estudos de dogmática jurídica, que visam à reconstrução de um determinado sistema, tendo em vista o desenvolvimento dos princípios jurídicos e a sua aplicação para a solução de novos casos.

Essa advertência, de caráter preliminar, não deve ser esquecida no estudo do direito comparado.

Entretanto, o conhecimento do direito comparado constitui, por seu turno, sob os dois aspectos acima lembrados, um auxílio para a interpretação e a aplicação em geral com os estudos históricos e sociológicos." ASCARELli, Tullio. Problemas das Sociedades Anônimas e Direito Comparado. Campinas: Bookseller, 1999, pgs. 44 e 45.
} 
contraposição ao disposto na legislação nacional e as eventuais limitações jurídicas impostas às suas atividades. 


\section{CAPÍTULO VI - CONCLUSÃo}

Os Comitês são mais uma alternativa encontrada na eterna (e quase utópica) busca por um sistema de administração que seja ao mesmo tempo (i) eficiente e (ii) livre de $\operatorname{conflitos}^{442}$.

No quesito eficiência, os Comitês se apresentam como órgãos especializados, que profissionalizam a gestão das companhias e, consequentemente, contribuem para que sejam utilizadas as melhores técnicas na gestão.

Quando o objetivo dos Comitês fica restrito à busca por eficiência, difícil é imaginar situações em que esses órgãos não sejam bem-vindos. Acionistas, controladores ou não-controladores, e administradores só têm a ganhar com o aprimoramento da eficiência na gestão da companhia.

Porém, o fator eficiência, por si só, não é o que justifica o clamor pelos Comitês no ambiente internacional. Pretende-se que esses órgãos atuem além da técnica, para identificar eventuais ocorrências que possam revelar alguma espécie de conflito de interesses.

Para que alcancem esse outro objetivo, a pesquisa realizada para o presente trabalho demonstrou que, na maior parte dos casos, será preciso prezar pela (i) independência dos membros dos Comitês, com relação às partes detentoras do "poder de dominação" ${ }^{443}$ que se faça presente na companhia; e (ii) transparência dos trabalhos e conclusões alcançadas pelos Comitês. Esses dois elementos, combinados ou não, definirão a força dos Comitês para combater os conflitos de interesses que afetam companhias.

\footnotetext{
442 "no fundo, quase quatrocentos anos volvidos sobre o despontar das primeiras sociedades anónimas, o regime da administração destas sociedades continua pré-ordenado àquele mesmo desígnio de permitir o domínio sobre a empresa a quem não 'domina' o capital social, ou, se preferir, de facultar a disseminação do capital sem a correspondente disseminação de poder dentro da sociedade."

MAIA, Pedro. Função e funcionamento do Conselho de Administração da Sociedade Anónima. Coimbra: Coimbra, 2002, p. 312.

${ }^{443}$ Expressão utilizada por COMPARATO, na sua famosa obra sobre o "poder de controle". COMPARATO, Fabio Konder. O poder de controle na sociedade anônima. cit., p. 16.
} 
No Brasil, ainda que seja possível constatar a influência gerada pelo clamor internacional, a criação dos Comitês pelas companhias ainda não pode ser traduzida como uma busca por alternativas para a luta contra os problemas de conflito.

Não costuma haver preocupação nem mesmo com a transparência dos trabalhos dos Comitês - quesito este que é muito mais fácil de ser implantado do que o da independência. A prova disso se dá com a simples leitura dos estatutos das companhias. Mesmo quando há alguma previsão mais detalhada sobre esses órgãos, é muito raro haver a exigência de divulgação de relatórios ou mesmo atas das reuniões realizadas.

Assim, se nem mesmo os estatutos sociais costumam impor a transparência para os trabalhos dos Comitês, muito mais difícil será exigi-la com base na interpretação da lei, que, como visto, não trata com clareza nem desse, nem de muitos outros assuntos afetos à atividade dos Comitês.

Aliás, a omissão legal sobre os Comitês dá azo a debates jurídicos muito profundos, os quais podem conduzir às mais díspares conclusões. Em alguns casos será inevitável encarar, com algum grau de inovação, alguns dos problemas enfrentados na adaptação desses órgãos ao sistema local. É o que já se disse, por exemplo, sobre o problema dos conflitos de competências intraorgânicas e da extensão das funções de monitoramento dos Comitês.

Podem-se mencionar, ainda, os problemas de distribuição de responsabilidades em face da heterogeneidade na composição dos Comitês (que podem contar, ao mesmo tempo, com administradores, não-administradores e representantes dos acionistas, por exemplo), bem como a questão da redução ou aumento das responsabilidades dos membros do Conselho de Administração vis-à-vis a responsabilidade dos membros dos Comitês ${ }^{444}$.

$\mathrm{Na}$ medida em que as atividades dos Comitês se desenvolvam, propõe-se que esses e outros temas sejam objeto de trabalhos futuros, para garantir a coesão jurídica no processo de adaptação desses órgãos nas companhias nacionais.

\footnotetext{
${ }^{444}$ Problema esse enfrentado pela primeira vez no julgamento do Processo Administrativo Sancionador CVM
} $\mathrm{n}^{\circ} 18 / 10$. Ver nota 362 e texto relacionado. 
Enquanto isso, este trabalho serviu para demonstrar parte do que já está disponível sobre o tema. Nesse ponto, chamam atenção as medidas das autoridades reguladoras, que fornecem algumas balizas para o que se espera dos Comitês. O problema da previsão estatutária, como visto, já pode ser interpretado conforme alguns nortes da CVM sobre o assunto. Assim como a questão da transparência está sendo melhor trabalhada nessa seara.

Enfim, o estudo dos Comitês faz transparecer alguns problemas clássicos do processo de importação de soluções que, originalmente, foram projetadas para funcionar em sistemas alienígenas. A consciência disso é a base para qualquer estudo que vise a analisar as possíveis formas de adaptação desses órgãos à realidade brasileira. 


\section{BIBLIOGRAFIA}

ABREU, Jorge Manuel Coutinho de. Governação das Sociedades Comerciais. Coimbra: Almedina, 2010.

ADAMEK, Marcelo Vieira von. Responsabilidade civil dos administradores de S/A (e ações correlatas). São Paulo: Saraiva, 2009.

ANDRADE, Adriana; ROSSETTI, José Paschoal. Governança Corporativa: fundamentos, desenvolvimento e tendências. São Paulo: Atlas, 2006.

ARMOUR, John. JACOBS, Jack B.. MILHAUPT, Curtis J. The Evolution of Hostile Takeover Regimes in Developed and Emerging Markets in Harvard International Law Journal, vol. 52, number 1, 2011.

ASCARELli, Tullio. Problemas das Sociedades Anônimas e Direito Comparado. Campinas: Bookseller, 1999.

BAINBRIDGE, Stephen M., Dodd-Frank: Quack Federal Corporate Governance Round II in UCLA School of Law, Law-Econ Research, Paper n ${ }^{\circ}$ 10-12, 2010.

BARNARD, Jayne W. Institutional Investors and the new Corporate Governance in North Carolina Law Review, nº 69, 1991.

BATALHA, Wilson de Souza Campos. Comentários à Lei das Sociedades Anônimas. Rio de Janeiro: Forense. 1977.

BHAGAT, Sanjai et. al. Hostile Takeovers in the 1980s: The Return to Corporate Specialization in Brookings Papers on Economic Activity. Microeconomics, vol. 1990, 1990.

BILL, Arthur H. Audit Committee Guide. New York: Bowne, 2008.

BLACK, Bernard S. Agents Watching Agents: The Promise of Institutional Investor Voice in UCLA Law Review, vol. 39, 1992

BLACK, Bernard S. CARVALHO, Antonio Gledson de. GORGA, Érica, An Overview of Brazilian Corporate Governance in Cornell Law Faculty Publications. Paper n 101, 2008.

BLAIR, Margaret M. Reforming Corporate Governance: What history can teach us in Berkeley Business Law Journal, 2003. 
BLAIR, Margareth M. Ownership and control: rethinking corporate governance for the twenty-first century. Washington: The Brookings Institution, 1995.

BRANCO, Adriano Castelo. O Conselho de Administração nas Sociedades Anônimas. 2. ed. Rio de Janeiro: Universitária, 2007.

BRAIOTTA, Louis, et AL. The Audit Committee Handbook - Fifth Edition. New Jersey: Wiley, 2010.

BRATTON, William W., Enron and the Dark Side of Shareholder Value - Georgetown Law Faculty Publications and Other Works in Tulane Law Review, 2002.

BRAUNBECK, Guillermo Oscar. Determinantes da Qualidade das Auditorias Independentes no Brasil. Tese - Faculdade de Economia, Administração e Contabilidade da Universidade de São Paulo, 2010.

BRUDNEY, Victor. The Independent Director: Heavenly City or Potemkin Village? in Harvard Law Review volume 95, nº 3, 1982.

BULGARELLI, Waldírio. Apontamentos sobre a responsabilidade dos administradores das companhias in Revista de Direito Mercantil, Industrial, Econômico e Financeiro. São Paulo: Revista dos Tribunais, $\mathrm{n}^{\circ} 50,1983$.

BULGARELLI, Waldírio. O Conselho Fiscal nas Companhias Abertas Brasileiras. São Paulo: Revista dos Tribunais, 1988.

CADBURY, Adrian. The Committee on Financial Aspects of Corporate Governance. London: Gee, 1992.

CARMO, Eduardo de Souza. Relações Jurídicas na Administração da S.A. Rio de Janeiro: Aide, 1988.

CARVAlHOSA, Modesto. Comentários à Lei das Sociedades Anônimas, $5^{\mathrm{a}}$ ed.. São Paulo: Saraiva, 2011.

CHOI, Stephen. Law, Finance and Path Dependence: Developing Strong Securities Markets in Texas Law Review, Forthcoming Symposium, 2002.

COFFEE, John C. BLACK, Bernard S. Hail Britannia?: Institutional Investor Behavior Under Limited Regulation in Michigan Law Review, vol. 92, 1994. 
COFFEE, John C. Jr. Inventing a Corporate Monitor for Transitional Economies in Comparative Corporate Governance: The State of the Art and International Regulation in The American of Society of Comparative Law, volume 59, issue 1, 2011.

. Liquidity versus Control: The Institutional Investor as Corporate Monitor in Columbia Law Review, vol. 91, nº 6, 1991.

. Racing towards the Top?: The Impact of Cross-Listings and Stock Market Competition on International Corporate Governance in Columbia Law Review, vol. 102, $\mathrm{n}^{\mathrm{o}} 7,2002$.

. The Future as History: The Prospects for Global Convergence in Corporate Governance and its Implications in Columbia Law School Center for Law and Economic Studies, working paper $\mathrm{n}^{\circ} 144,1999$.

, A Theory of Corporate Scandals: Why the U.S. and Europe Differ in Columbia Lawand Economics. Working Paper No. 274., 2005.

COLLIER, Paul and ZAMAN, Mahbub. Convergence in European Corporate Governance: the audit committee concept in Corporate Governance: An International Review, vol. 13, 2005.

. The rise of the audit committee in UK quoted companies: a curious phenomenon? in Accounting, Business \& Financial History. Volume 6, issue 2, 1996.

COMPARATO, Fabio Konder. A natureza da sociedade anônima e a questão da derrogabiliadde das regras legais de quorum nas assembleias gerais e reuniões do Conselho de Administração in Novos Ensaios e Pareceres de Direito Empresarial. Rio de Janeiro: Forense, 1981.

. Aspectos Jurídicos da Macroempresa, São Paulo: Revista dos Tribunais, 1970. O poder de controle na sociedade anônima. $3^{\mathrm{a}}$ ed. Rio de Janeiro: Forense, 1983.

CONYON, Martin J. Corporate Governance Changes in UK Companies Between 1988 and 1993 in Corporate Governance: An International Review, vol. 2, issue 2, 1994.

CORDEIRO, Antonio Menezes Cordeiro. Manual de Direito das Sociedades. Das Sociedades em Especial. $2^{\text {a }}$ ed. Coimbra: Almedina, 2007. 
CORREIA, Luís Brito. Os Administradores de Sociedades Anónimas. Coimbra: Almedina, 1993.

CROMME, Gerhard. Corporate Governance in Germany and the German Corporate Governance Code in Corporate Governance: An International Review, volume 13, $\mathrm{n}^{\circ} 3$, 2005 .

. Publication of the draft German Corporate Governance Code, 2001, Düsseldor. Disponível em:

http://www.corporate-governance-code.de/eng/download/RedeDrCromme_e.pdf

CRISTIANO, Romano. Órgãos da Sociedade Anônima. São Paulo: Revista dos Tribunais, 1982.

DAHYA, Jay, McCONNELL, John J. and TRAVLOS, Nickolaos H. The Cadbury Committee, Corporate Performance and Top Management Turnover. The Journal of Finance, nol. 57, $\mathrm{n}^{\mathrm{o}}$ 1, 2002.

DAVIES, Paul L. Principles of Modern Company Law, 8th edition, Londres: Sweet \& Maxwell, 2008.

Board Structure in the UK and Germany: Convergence or Continuing Divergence? working paper, 2001. Disponível em: http://ssrn.com/abstract=262959

DEAKIN, Simon. HUGHES, Alan. Directors' Duties: Empirical Findings - Report to the Law Commissions. University of Cambridge, 1999. Disponível em:

http://www.justice.gov.uk/lawcommission/docs/lc261_Company_Directors_ESRC_Resear ch.pdf.

DOIDGE, Craig, et. al. Private Benefits of Control, Ownership, and the Cross-listing Decision in The Journal of Finance, vol. LXIV, nº 1, 2009.

EIZIRIK, Nelson, Limites à atuação do Conselho Fiscal. in Revista de Direito Mercantil, Industrial, Econômico e Financeiro. São Paulo: Revista dos Tribunais, nº 84.

FALEYE, Olubunmi. HOITASH, Rani. HOITASH, Udi. Advisory Directors, 2011. Disponível em:

http://ssrn.com/abstract=1866166

FERRARINI, Guido, et al. Reforming Company and Takeover Law in Europe. New York: Oxford, 2004. 
FICHTNER, Jason Royce. The recent international growth of mandatory audit committee requirements. International Journal of Disclosure and Governance, volume 7, número 3, 2010.

FOX, Merritt B. Required Disclosure and Corporate Governance in Comparative Corporate Governance: The State of the Art and International Regulation. New York: Oxford.

FURUTA, Fernanda. A relação das características das empresas com a adoção do Comitê de Auditoria X Conselho Fiscal adaptado. Tese - Faculdade de Economia, Administração e Contabilidade da Universidade de São Paulo, 2010.

GILSON, Ronald J. Globalizing Corporate Governance: Convergence of Form or Function in Stanford Law and Economics Olin. Working Paper n 192, 2000.

GILSON, Ronald J. KRAAKMAN, Reinier H. Reinventing the Outside Director: An Agenda for Institutional Investors in Stanford Law Review, vol. 43, n 4, 1991.

GLAESER, Edward L. SHLEIFER, Andrei. Legal Origins in Harvard Institute of Economic. Research Paper nº 1920, 2001.

GORGA, Érica. Changing the Paradigm of Stock Ownership from Concentrated Towards Dispersed Ownership? Evidence from Brazil and Consequences for Emerging Countries in Forthcoming Northwestern Journal of International Law \& Business. 2009.

GOULDING, Simon. Company Law - 2nd ed. London: Cavendish, 1996.

HAMILTON, Robert W. Corporate Governance in America 1950-2000: Major Changes but Uncertain Benefits in Journal of Corporation Law, 25, 1999-2000.

. The Crisis in Corporate Governance: 2002 Style in 40 Houston Law Review, 2003.

HAMPEL, Ronnie. Committee on Corporate Governance. Final Report. London: Gee, 1998.

HART, Oliver. Corporate Governance: Some Theory and Implications in The Economic Journal, vol. 105, nº 430, 1995.

HERZEL, Leo. Board of Directors versus Institutional Investors in Institutional Investors and Corporate Governance, Berlim; Nova York: de Gruyter, 1993. 
HOFSTETTER, Karl. One size does not fit all: Corporate Governance for 'Controlled Companies' in North Carolina Journal of International Law and Commercial Regulation, $n^{\circ} 31,2005$.

HOPT, Klaus J. Comparative Corporate Governance: The State of the Art and International Regulation. New York: Oxford, 1998.

. The German Two-Tier Board: Experience, Theories, Reforms in Comparative Corporate Governance: The State of the Art and International Regulation in The American of Society of Comparative Law, volume 59, issue 1, 2011.

JENSEN, Michael C.; MECKLING, William. A theory of the firm: governance, residual claims and organizational forms, Journal of Financial Economics, vol. 3, nº 4, 1976.

JENSEN, Michael C., The Modern Industrial Revolution, Exit, and the Failure of Internal Control Systems in Harvard University Press, 2000.

KALANSKY, Daniel. Incorporação de Ações - Estudo de casos e precedentes. São Paulo: Saraiva, 2011.

KEASEY, et al. Corporate Governance - Accountability, Enterprise and International Comparisons, New Jersey: Wiley. 2005.

KLEIN, April. Firm Performance and Board Committee Structure in Journal of Law and Economics, volume 41, no $1,1998$. . Audit committee, board of director characteristics, and earnings management in Journal of Accounting and Economics, v. 33, 2002.

KÖHLER, Annette G. Audit Committees in Germany - Theoretical Reasoning and Empirical Evidence in Schmalenbach Business Review, vol. 57, 2005.

KRAAKMAN, Reiner, et al. The Anatomy of Corporate Law. Second Edition, New York: Oxford, 2009.

LA PORTA, Rafael. et al. Law and Finance in Journal of Political Economy, volume 106, $n^{\circ} 6,1998$.

LA PORTA, Rafael. SILANES, Florencio Lopez. SHLEIFER, Andrei. The Economic Consequences of Legal Origins in Journal of Economic Literature, 46:2. 
LA PORTA, Rafael. LOPEZ DE SILANES, Florencio. SHLEIFER, Andrei. Corporate Ownership Around the World in Harvard Institute of Economic, Research Paper $\mathrm{n}^{\mathrm{o}}$ 1840, 1998.

LAMY FILHO, Alfredo. Temas de S.A. - Exposições e Pareceres. Rio de Janeiro: Renovar, 2007.

LAMY FILHO, Alfredo. Remuneração do Conselho Consultivo com Participação nos Lucros in A Lei das S.A. - Pareceres. Volume II, 2a Edição, Rio de Janeiro: Renovar, 1996. LAMY FILHO, Alfredo, PEDREIRA, José Luiz Bulhões. Estrutura da Companhia in Direito das Companhias, vol. I, Rio de Janeiro: Forense, 2009.

LANNOO, Karel. A European Perspective on Corporate Governance in Journal of Common Market Studies, volume 37, issue 2, 1999.

LEÃES, Luiz Gastão Paes de Barros. Pareceres - volume 1. São Paulo: Singular, 2004.

LOPES, Alexandro Broedel. Earnings Management and Corporate Governance: Legal and Regulatory Implications. Revista de Direito Mercantil, Industrial, Econômico e Financeiro. São Paulo: Revista dos Tribunais, n $^{\circ}$ 158, 2011.

O Novo Regime Jurídico das Demonstrações Financeiras das Companhias Abertas Brasileiras: Algumas Implicações para o Direito Societário, artigo inédito, [s.d.]. . The relation Between Firm-Specific Corporate Governance, Cross-listing and the Informativeness of accounting numbers in Brazil. Tese - Manchester Business School, 2009.

MACEY, Jonathan R. Corporate Governance: Promises Kept, Promises Broken. Princeton: Princeton University Press, 2010.

MAHER, Maria E. ANDERSSON, Thomas. Corporate Governance: Effects on Firm Performance and Economic Growth, 2000.

MAIA, Pedro. Função e funcionamento do Conselho de Administração da Sociedade Anónima. Coimbra: Coimbra, 2002.

MARTINS, Frans. Comentários à Lei das Sociedades Anônimas. Rio de Janeiro: Forense, 1978.

Curso de Direito Comercial. Rio de Janeiro: Forense, 2008. 
MCCONVILL, James. BAGARIC, Mirko. Towards Mandatory Shareholder Committees in Australian Companies in Melbourne University Law Review, vol. 28, 2004.

MILHAUPT, Curtis J. PISTOR, Katharina. Law and Capitalism - What Corporate Crises Reveal about Legal Systems and Economic Development around the World. Chicago and London: University of Chicago Press, 2008.

MIZRUCHI, Mark S. Berle and Means revisited: the governance and power of large U.S. corporations. New York: Springer, 2004

MOBLEY, Martin D., Compensation Committee Reports Post-Sarbanes-Oxley: Unimproved Disclosure of Executive Compensation Policies and Practices in, Columbia Business Law Review, 111, 2005.

MORTIMORE, Simon. Company Directors - Duties, Liabilities, and Remedies. New York: Oxford. 2009.

MUNHOZ, Eduardo Secchi. Desafios do Direito Societário Brasileiro na Disciplina da Companhia Aberta: Avaliação dos sistemas de controle diluído e concentrado in Direito Societário, Desafios Atuais. São Paulo: Quartier Latin, 2009.

Empresa Contemporânea e Direito Societário. São Paulo: Juarez, 2002.

MYERS, Patricia M., ZIEGENFUSS, Douglas E., Audit committee pre-Enron efforts to increase the effectiveness of corporate governance in Corporate Governance, vol. 6, 2006.

NEVES, Vanessa Ramalhete Santos. Responsabilidade dos Administradores das Sociedades Anônimas. Rio de Janeiro: Lumen, 2002.

O’BRIEN, Justin. Redesigning Financial Regulation. New Jersey: Wiley, 2007.

PALEPU, Krishna and HEALY, Paul M., The Fall of Enron in Journal of Economic Perspectives, vol. 17, n 2, 2003.

PEIXOTO, Carlos Fulgêncio da Cunha. Sociedades por Ações. $4^{\circ}$ Volume, São Paulo: Saraiva, 1973.

PERRY, Tod. ZENNER, Marc. Pay for Performance? Government Regulation and the Structure of Compensation Contracts in Journal of Financial Economics, $\mathrm{n}^{\circ}$ 62, 2001 ..

PISTOR, Katharina. et. Al. The Evolution of Corporate Law - A Cross-Country Comparison in The University of Pennsylvania Journal of International, volume 23, issue 4. 
PONTES, Evandro Fernandes. Conselho Fiscal nas Companhias Abertas Brasileiras. Tese - Faculdade de Direito da Universidade de São Paulo, 2009.

QUICK, Reiner. TURLEY, Stuart. WILLEKENS, Marleen. Auditing, trust and governance: regulation in Europe. London: Taylor \& Francis, 2008.

REQUIÃO, Rubens. Curso de Direito Comercial.São Paulo: Saraiva, 2008.

RIBEIRO, Renato Ventura. Deveres de Diligência dos Administradores das Sociedades. São Paulo: Quartier Latin, 2006.

ROE, Mark J. A political theory of American corporate finance in Columbia Law Review vol. $91, \mathrm{n}^{\circ} 1,1991$.

. Chaos and Evolution in Law and Economics in Harvard Law Review, 109, 1996.

. Corporate Governance in Germany, Japan and America in Institutional Investors and Corporate Governance, Berlim; Nova York: de Gruyter, 1993.

_. Takeover Politics in The Deal Decade. Washington DC: Brookings Institution, 1993.

ROE, Mark J., BEBCHUK, Lucian A. A Theory of Path Dependence in Corporate Governance and Ownership in Stanford Law Review, vol. 52, 1999.

ROMANO, Roberta. Public Pension Fund Activism in Corporate Governance Reconsidered in Institutional Investors and Corporate Governance, Berlim; Nova York: de Gruyter, 1993.

ROWLAND, Gregory S. Earnings Management, the SEC, and Corporate Governance: Director Liability Arising from the Audit Committee Report in Columbia Law Review, vol. $102, \mathrm{n}^{\mathrm{o}} 1,2002$.

RYAN, Christopher. Company Diretctors. Liabilities, Rights and Duties. Oxford: CCH, 1990.

SALOMÃO FILHO, Calixto. O novo direito societário, $4^{\mathrm{a}}$ ed., São Paulo: Malheiros, 2011.

SANTOS, Aline de Menezes. A governança corporativa das empresas no Brasil: uma abordagem jurídica inspirada na nova economia institucional e na teoria organizativa. Dissertação - Faculdade de Direito da Universidade de São Paulo, 2009. 
STIGLER, George J. FRIEDLAND, Claire. The Literature of Economics: The Case of Berle and Means in Journal of Law and Economics, vol. 26, $\mathrm{n}^{\circ} 2$.

THOMSEN, Steen. Convergence goes both ways: An alternative perspective on the convergence of corporate governance systems in European Business Organization Law Review, vol. 4, 2003.

TOLEDO, Paulo Fernando Campos Salles de. O Conselho de Administração da sociedade Anônima. São Paulo: Atlas, 1997.

TEIXEIRA, Egberto Lacerda; GUERREIRO, José Alexandre Tavares. Das Sociedades Anônimas no Direito Brasileiro. São Paulo: Bushatsky, 1979.

TRICKER, Bob. Corporate Governance - Principles, Policies, and Practices. New York: Oxford, 2009.

VAFEAS, Nikos, THEODOROU, Elena. The relationship between board structure and firm performance in the UK in The British Accounting Review, volume 30, issue 4, 1998.

Audit Committees, Boards, and the Quality of Reported Earnings in Contemporary Accounting Research, vol. 22, issue 4, 2005

VALVERDE, Trajano de Miranda. Sociedades por ações. Rio de Janeiro: Forense, 1959, v. 2.

VERSCHOOR, Curtis C. Audit Committee Essentials. New Jersey: Wiley, 2008.

WEIR, Charlie. LAING, David. MCKNIGHT, Phillip J. Internal and External Governance Mechanisms: Their Impact on the Performance of Large UK Public Companies in Journal of Business Finance \& Accounting, n 29, 2002.

XIE, Biao, DAVIDSON, Wallace N. and DADALT, Peter J. Earnings Management and Corporate Governance: The Roles of the Board and the Audit Committee in Journal of Corporate Finance, vol. 9, 2001

YAZBEK, Otavio. Regulação do Mercado Financeiro e de Capitais. Rio de Janeiro: Elsevier, 2007.

_. Representações do dever de diligência na doutrina jurídica brasileira: um exercício e alguns desafios, artigo inédito, [s.d.]. 